\title{
COMMENT
}

\section{The Equal Opportunity Act 2010 (Vic) Review Function: 'Soft' Regulation or an Effective Tool to Promote Transparency and Equality?}

Simone Cusack ${ }^{(\mathbb{D})}$, Director of Policy and Research at the Victorian Equal Opportunity and Human Rights Commission, Australia

\section{ABSTRACT}

Regulatory triggers can provide a powerful motivator for transparency, including its implied expectations of openness and accountability. This includes section 151 of the Equal Opportunity Act 2010 (Vic), which enables the Victorian Equal Opportunity and Human Rights Commission to review a duty holder's "programs and practices" to determine their compliance with the Act. This article argues that the exercise of the review function in section 151 supports transparency through the level of access to people and information it affords and the ability for the Commission to critically and openly assess the state of equality in a duty holder's organisation. This level of access and openness encourages accountability and helps to persuade and motivate duty holders to take measurable steps towards achieving equality and compliance with the Equal Opportunity Act. Surprisingly little is known, however, about this regulatory tool and its facilitative approach to compliance. This article seeks to build awareness and understanding of the review function and critically analyses its potential to promote transparency and equality. It suggests that the review function is a tool deserving of greater consideration, particularly by duty holders, in efforts to achieve substantive equality.

Keywords - Equality, Positive duty, Transparency, Regulation, Independent reviews

Acknowledgements: The views expressed in this article are those of the author and do not necessarily reflect the views of the Commission. The author would like to thank Emerita Professor Margaret Thornton, Associate Professor Dominique Allen and Associate Professor Alysia Blackham for their vision in hosting a conference on Using Transparency to Achieve Equality at such an important moment in time and for persevering despite the uncertain and constantly changing environment arising from a global health emergency. The author would also like to thank the other conference participants for their insightful presentations and comments.

Disclosure statement: No potential conflict of interest was reported by the author.

License: This work is under Attribution-NonCommercial-ShareAlike 4.0 International (CC BY-NC-SA 4.0)

https://creativecommons.org/licenses/by-nc-sa/4.0/

Suggested citation: Cusack, S. 2021. "The Equal Opportunity Act 2010 (Vic) Review Function: 'Soft' Regulation or an Effective Tool to Promote Transparency and Equality?" Law in Context, 37 (2):132-144, DOI: http://doi.org/10.26826/law-in-context.v37i2.159

\section{Summary}

1. Introduction

2. The Equal Opportunity Act 2010

2.1. Objectives

2.2. Regulatory framework

3. Promoting transparency and equality through the independent review function

3.1. The scope and limits of section 151
3.1.1. Policy intent
3.1.2. Formal request to conduct a review

3.1.3. Considerations that inform a decision to conduct a review

3.1.4. The conduct of reviews

3.1.5. Review outcomes: A case study

3.2. A regulatory tool to promote transparency and equality

3.3. Early lessons from completed reviews

4. Conclusion

5. References 


\section{INTRODUCTION}

The end of 2020, and the start of what is commonly hoped will be a vastly different year in 2021, saw an outpouring of individual and collective reflections about the learnings that have emerged so far from the COVID19 pandemic. Perhaps unsurprisingly given the extraordinary powers that governments have exercised in an effort to conquer the global public health emergency often with far-reaching consequences for people's human rights - the importance of transparency has been critical among them.

While the concern for transparency is not new and is even encouraged in existing legislative frameworks (see, for example, the Charter of Human Rights and Responsibilities Act 2006 (Vic)), it would seem that the pandemic has crystallised the importance of transparency in our day-to-day lives, whether in relation to decisions about our ability to move freely across state and national borders or, for example, to assemble peacefully. The increased individual and community focus on transparency seems unlikely to abate, at least in the immediate future. Instead, it seems more likely that it will take on even greater importance as we seek to rebuild our communities and livelihoods during recovery-hopefully, shunning the entrenched structural inequalities that have played out over the past year to devastating effect. The beginning of this new year therefore provides a timely opportunity to reflect on the various mechanisms at our disposal to promote and achieve transparency, whether in government decision-making related to the pandemic or in the way that all duty holders at any point in time implement their obligations to uphold human rights, including the rights to non-discrimination and equality.

Regulatory triggers can provide a powerful motivator for transparency, including its implied expectations of openness and accountability. An effective, although perhaps lesser known, example is section 151 of the
Equal Opportunity Act 2010 (Vic), which enables the Victorian Equal Opportunity and Human Rights Commission to review a duty holder's "programs and practices" to determine their compliance with the Act, when requested to do so by that duty holder. ${ }^{1}$

At its core, the review function exists to support duty holders to comply with the Equal Opportunity Act. At the same time, as this article argues, this voluntary regulatory tool affords the Commission and, through it, the public, a rare and detailed insight into the state of equality in the requesting duty holder's organisationinsight of a scale otherwise infrequently obtained. ${ }^{2}$ Not only is the level of access to information about the state of equality remarkable, but the knowledge that the Commission can detail its findings and recommendations in a public report has so far proven to be a powerful motivator for duty holders to take measurable steps towards achieving equality and compliance with the Equal Opportunity Act. Perhaps somewhat surprisingly at first glance, knowledge of this very openness has even been a key reason why some duty holders have invited the Commission to conduct an independent review of their organisation.

This article begins in Section 2 by briefly canvassing the objectives of the Equality Opportunity Act and contextualising the review function within the Act's broader regulatory framework. Section 3 seeks to build awareness and understanding of the review function, detailing the scope and limits of section 151 and exploring examples where the function has been exercised by the Commission. In doing so, it critically analyses the potential of the function to promote transparency and reflects on early learnings about the elements of a review that are likely to propel a duty holder to take meaningful steps towards achieving equality. Section 4 concludes by arguing that there is an emerging body of evidence demonstrating that section 151 can be an effective

\footnotetext{
${ }^{1}$ See also section 41(c) of the Charter of Human Rights and Responsibilities Act 2006 (Vic), which enables the Commission, "when requested by a public authority, to review that authority's programs and practices to determine their compatibility with human rights".

${ }^{2}$ A notable exception would be the establishment of a Royal Commission under the Inquiries Act 2014 (Vic), directed in its Letters Patent to examine matters related to discrimination, sexual harassment and/or victimisation within particular organisations.
} 
regulatory tool to promote and achieve transparency and equality. On this basis, it suggests that the review function is a tool deserving of greater consideration, particularly by duty holders, in efforts to achieve substantive equality.

\section{THE EQUAL OPPORTUNITY ACT}

\subsection{OBJECTIVES}

The Equal Opportunity Act provides a framework for protecting Victorians against discrimination, sexual harassment and victimisation. Its stated objectives include to eliminate discrimination, sexual harassment and victimisation and their systemic causes to the greatest extent possible, ${ }^{3}$ and to "promote and facilitate the progressive realisation of equality, as far as reasonably practicable". ${ }^{4}$ In the case of the latter objective, this includes by recognising that reasonable adjustments and special measures may be required to achieve substantive equality. ${ }^{5}$

The Equal Opportunity Act seeks to achieve these objectives by prohibiting discrimination, sexual harassment and victimisation in employment, education and certain other areas of public life. ${ }^{6}$ It also imposes a "positive duty" to take reasonable and proportionate measures to eliminate discrimination, sexual harassment and victimisation. ${ }^{7}$ This duty-currently the only one in Australian anti-discrimination law-requires duty holders to be proactive about prevention, rather than simply reacting to individual complaints of unlawful conduct. In doing so, it encourages compliance, even in the absence of an individual complaint (Gardner 2008).

\subsection{REGULATORY FRAMEWORK}

The Equal Opportunity Act establishes a regulatory framework that vests the Commission with a broad spectrum of functions that it can use to promote the objectives of the Act.

The Act provides that the Commission is an advocate for the Act, promoting and advancing its objectives and raising community awareness about the importance of equality. ${ }^{8}$ It states that the Commission can inform and educate ${ }^{9}$ providing information to help people understand and assert their rights and duty holders to know and understand their legal obligations so that they might comply with them. This includes undertaking and sharing research into the systemic causes of, and solutions for, inequality. 10 The Act confers on the Commission the power to set standards. ${ }^{11}$ These "practice guidelines", as they are known, inform duty holders of their obligations under the Act and support them to comply, as in the case of the Commission's guideline on preventing and responding to workplace sexual harassment (Victorian Equal Opportunity and Human Rights Commission 2020). The Act also empowers the Commission to provide independent expert advice and guidance to support duty holders to know and understand their obligations and, importantly, strengthen their compliance capabilities. This includes by conducting voluntary reviews resulting in practical advice on how to comply with the Act and remedy any non-compliance, ${ }^{12}$ and by

${ }^{3}$ Equal Opportunity Act 2010 (Vic) ss 3(a), 3(c).

${ }^{4}$ Equal Opportunity Act 2010 (Vic) s 3(d).

${ }^{5}$ Equal Opportunity Act 2010 (Vic) s 3(d)(iii).

${ }^{6}$ Equal Opportunity Act 2010 (Vic) pt 4, 6 and 7.

${ }^{7}$ Equal Opportunity Act 2010 (Vic) s 15.

${ }^{8}$ Equal Opportunity Act 2010 (Vic) s 155(1)(b).

${ }^{9}$ Equal Opportunity Act 2010 (Vic) ss 155(1)(a), 156(1).

${ }^{10}$ Equal Opportunity Act 2010 (Vic) s 157.

${ }^{11}$ Equal Opportunity Act 2010 (Vic) s 148(1). While not legally binding, section 149 of the Act provides that these guidelines are authoritative in that a court or the Victorian Civil and Administrative Tribunal (VCAT) may consider evidence of compliance with them if relevant to a case under the Act. The Commission can also consider such guidelines when conducting investigations under Part 9 of the Act.

${ }^{12}$ Equal Opportunity Act 2010 (Vic) s 151. 
advising duty holders on preparing and implementing equal opportunity action plans. ${ }^{13}$ It also includes intervening in court proceedings ${ }^{14}$ and assisting in proceedings as amicus curiae. ${ }^{15}$ And, finally, the Act authorises the Commission to resolve complaints of unlawful conduct under the Act ${ }^{16}$ and enables it to monitor and investigate compliance with the Act. ${ }^{17}$

Common to many of the functions vested in the Commission under the Equal Opportunity Act is an assumption that educating duty holders about their obligations, ensuring that they know how to comply with those obligations and improving their capability to do so, will increase compliance and, in turn, strengthen equality outcomes across the state. Time and again, but particularly through independent reviews, the Commission has witnessed the transformational change that can be achieved through such a facilitative approach to compliance. ${ }^{18}$ Yet, the limited enforcement powers conferred on the Commission in the Act, 19 whether in relation to the review or other functions, can constrain its ability to support greater change, particularly when information, education, advice and guidance fail to bring about much needed change.

\section{PROMOTING TRANSPARENCY AND EQUALITY THROUGH THE INDEPENDENT REVIEW FUNC- TION}

Very little has been written so far about the review function in section 151 of the Equal Opportunity. Section 3 seeks to address this gap in the literature, detailing the policy, scope and limits of this section and outlining how it has been operationalised in practice, including in support of greater transparency and equality outcomes. Considering a number of completed and current reviews, it also reflects on early learnings about the elements of a review that guide a duty holder to take meaningful steps towards achieving equality.

\subsection{THE SCOPE AND LIMITS OF SECTION 151}

Section 151(1) of the Equal Opportunity Act provides that "[o]n request of a person, the Commission may enter into an agreement with the person to review that person's programs and practices to determine their compliance with this Act". ${ }^{20}$

${ }^{13}$ Equal Opportunity Act 2010 (Vic) s 152(2). While not legally binding, section 152(3) provides that a court or VCAT may consider an action plan if relevant to a case under the Act.

${ }^{14}$ Equal Opportunity Act 2010 (Vic) s 159.

${ }^{15}$ Equal Opportunity Act 2010 (Vic) s 160.

${ }^{16}$ Equal Opportunity Act 2010 (Vic) s 111.

${ }^{17}$ Equal Opportunity Act 2010 (Vic) s 127. The Commission may only conduct an investigation if: the matter raises an issue that is serious in nature, relates to a class or group of persons and cannot reasonably be expected to be resolved by dispute resolution or by making an application to VCAT under section 122; there are reasonable grounds to suspect that one or more contraventions of the Act have occurred; and the investigation would advance the Act's objectives.

${ }^{18}$ See Section 3.1.5.

${ }^{19}$ In 2010, the Victorian Government passed the Equal Opportunity Act 2010 (Vic), which, among other things, allowed the Commission to conduct investigations and public inquiries in certain circumstances, introduced enforcement mechanisms (for example, the power to issue compliance notices and enforceable undertakings) and strengthened the Commission's powers to compel information, documents and attendance in the context of an investigation or public inquiry. However, the Act was amended again in 2011 by the Equal Opportunity Amendment Bill 2011 (Vic), before the 2010 amendments commenced, resulting in the removal of the public inquiry function and the compliance powers, and more limited compulsion powers. The recently passed Change or Suppression (Conversation) Practices Prohibition Act 2021 (Vic) confers enforcement powers on the Commission, but only in relation to own-motion investigations into serious or systemic LGBTIQ change or suppression (conversion) practices. That Act, which is due to commence in February 2022, authorises the Commission to compel witnesses and the provision of documents, accept enforceable undertakings and issue compliance notices.

20 The review function in section 151(1) differs from the research function in section 157 of the Equal Opportunity Act insofar as an exercise of the former function is concerned with gathering and analysing information to determine whether a duty holder has complied with their obligations under the Act, while an exercise of the latter function focuses on gathering and analysing information but without having regard to the compliance of a duty holder or holders. See United Firefighters Union of Australia $v$ Victorian Equal Opportunity and Human Rights Commission [2018] VSCA 252 (Maxwell, P and Priest JA) (Maxwell, P and Priest JA) [62]. 


\subsubsection{POLICY INTENT}

The intent of the function is to encourage a duty holder, when needed, to seek the Commission's assistance to improve its compliance with the Equal Opportunity Act. ${ }^{21}$ In practice, reviews provide an opportunity for a duty holder to gain a deep understanding of the state of an issue (for example, race discrimination) within their organisation and its underlying drivers, one that is informed by rigorous independent research and broadranging stakeholder engagement. Reviews also enable the duty holder to identify any gaps in their compliance with the Act and receive practical and evidence-based solutions to support compliance.

Unlike more traditional inquiries or audits, reviews require the Commission to work closely and constructively with the duty holder, in a relationship that has come to be known as that of a "critical friend". Describing the relationship that evolved between Victoria Police and the Commission over the course of the Commission's five-year Independent review into sex discrimination and sexual harassment, including predatory behaviour, in Victoria Police, Commissioner Kristen Hilton reflected:

[t]his has been a unique partnership. We have played the role of auditor, expert advisor, confidante, supporter and, at times, critic. Both our organisations have approached our roles with firm intent, openness and a willingness to learn and pivot course where necessary. This continual learning has been important because, like any program that seeks to seriously disrupt the status quo, there have been a number of challenges: pockets of serious backlash; a long institutional memory; a demanding operational environment; and a catalogue of past harm, much of which is yet to be reconciled (Victorian Equal Opportunity and Human Rights Commission $2019, v)$.
In the Commission's experience, this facilitative approach to compliance, enabled by the review function, ultimately helps the duty holder to strengthen their compliance capabilities, which then serves to improve equality outcomes within the duty holder's organisation not only during the course of a review, but also beyond. Of course, this facilitative approach to compliance will not be sufficient to persuade all duty holders to act.

\subsubsection{FORMAL REQUEST TO CONDUCT A REVIEW}

Only the person upon whom obligations are imposed by the Equal Opportunity Act - the duty holder - can invite the Commission to conduct a compliance review of their organisation. ${ }^{22}$ As the majority of the Court of Appeal explained in United Firefighters Union of Australia $v$ Victorian Equal Opportunity and Human Rights Commission,

it is precisely because the Act imposes obligations on an individual employer [or other duty holder] that the question of compliance to which a review under s 151(1) is expressly directed is, necessarily, a question of compliance by that employer [or other duty holder] with its obligations. ${ }^{23}$

For the Commission's current Independent review into workplace equality in Ambulance Victoria, this formal request came from Board Chair Mr Ken Lay AO APM acting on behalf of the organisation (Lay, 2020), following allegations of sex discrimination, sexual harassment and bullying reported in Melbourne newspaper, The Age (Tuohy, 2020a; 2020b; 2020c).

The factors motivating a duty holder to invite the Commission to conduct a review, particularly a largescale review, are as diverse as the reviews themselves. At times the motivating factor or factors are external to

\footnotetext{
21 Ibid.

${ }^{22}$ United Firefighters Union of Australia v Victorian Equal Opportunity and Human Rights Commission [2018] VSCA 252 (Maxwell, $\mathrm{P}$ and Priest JA) [59], [62]. In this case, the Court of Appeal unanimously held that section 151(1) of the Equal Opportunity Act did not authorise the Commission's Independent Review into Equity and Diversity in CFA and MFB, as the "person" requesting the review (i.e., the Victorian Government) was not the "person" whose compliance with the Act was to be reviewed (i.e., the Country Fire Authority and the Metropolitan Fire Brigade): at [59] - [62].

${ }^{23}$ Ibid [59] [original emphasis].
} 
the duty holder, like when a body of inquiry recommends that the duty holder invite the Commission to conduct a review. ${ }^{24}$ Internal factors often also compel duty holders to request reviews. In the Commission's experience, requests are made when an organisation's senior leaders come to recognise that they are facing serious and systemic issues that tend to be cultural and/or structural in nature, issues that cannot reasonably be attributed to the actions of aberrant individuals or fixed quickly internally or without some kind of external expertise and accountability. Oftentimes, there will be a catalyst, an incident or development that shines a light on an existing underlying problem, one that may have attracted media attention or one that, for whatever reason, has not previously gained traction. Sometimes, it is the actions of one or more brave individuals who come forward and ensure that their experiences of discrimination, sexual harassment and/or victimisation are known - known so that others do not need to needlessly experience the same harm that they themselves have endured.

In the Commission's experience, such recognition is often accompanied by an acknowledgement among senior leaders that the organisation requires independent expert advice and guidance to support them to address the problem at hand and strengthen their compliance with the Act. As the regulator of Victoria's human rights laws, including the Equal Opportunity Act, the value of seeking a review by the Commission appears to be well understood.

Whether the initial motivations are external and/or internal, a driving impetus for many duty holders approaching the Commission with a request to conduct a review is the transparency, independent external oversight and accountability that such a review offers. It was for these very reasons that Mr Ken Lay AO APM, former Chief Commissioner of Police, invited the Commission to conduct a review into Victoria Police, the state's third largest public entity employer in the Victorian Public
Sector. "We could have undertaken an internal review", he said, "but that wouldn't have led to systemic change. We need change more quickly. Sunlight is the best disinfectant" (Victorian Equal Opportunity and Human Rights Commission 2015). Mr Graham Ashton AM APM, former Chief Commissioner and successor to Mr Lay, echoed this sentiment:

we thought, well, we can deal with these individual cases in terms of criminal conduct, and these cases were clearly in the criminal sphere, but we obviously had a bigger problem than that and we needed to seek systemic change and for that we needed expertise. And we had also the benefit through going to [the Commission] of having independence associated with that expertise (Ashton, G 2019).

\subsubsection{CONSIDERATIONS THAT INFORM A DECISION TO CONDUCT A REVIEW}

The Equal Opportunity Act does not require the Commission to conduct a review after receiving a request to do so. Rather, the decision whether to do so remains entirely within the Commission's discretion.

In practice, the Commission makes a decision to conduct or not to conduct a review having regard to considerations related to: its legal authority to conduct the proposed review under section 151; the likely impact that the review would have on the duty holder, the problem at hand and the Commission's governing laws and strategic priorities; the capability and capacity of the organisation to conduct the review at the time the request is made (or at some point in the future); and the risks involved in conducting the review, including to the proposed subjects of the review (for example, victim-survivors of sexual harassment, including sexual assault).

When making its determination, the Commission typically engages in extensive discussions with the duty holder, to understand their needs, circumstances and willingness and capability to implement any recommendations that might arise from the requested review.

\footnotetext{
${ }^{24}$ To the author's knowledge, external bodies have now recommended that five independent reviews be conducted using section 41(c) of the Charter. See McGregor 2019, 18; English 2020, 108; Victorian Ombudsman 2018, 66; $2017,102$.
} 
Such discussion might, for instance, involve exploring how the review can best further the objectives of the Equal Opportunity Act or widening or limiting the scope of the proposed review to ensure it has maximum effect.

\subsubsection{THE CONDUCT OF REVIEWS}

Once the Commission has received a request to conduct a review and agrees to do so, it will enter into an agreement with the duty holder. ${ }^{25}$ The Commission determines the scope of the review in consultation with the requesting duty holder. In the case of large-scale reviews, the focus of this article, the Commission typically details the agreed scope in written Terms of Reference and makes these publicly available (see, eg, Victorian Equal Opportunity and Human Rights Commission 2021). In addition to defining the subject matter of the review, the Terms of Reference routinely describe the elements, phases and deliverables of a review.

In the case of the Ambulance Victoria review, the Terms of Reference specify that the review will proceed in three distinct phases. During Phase 1, the Commission will examine the nature, extent, drivers and impact of discrimination, sexual harassment, victimisation and bullying within Ambulance Victoria and the adequacy of the organisation's responses to this unlawful conduct, detailing its findings and recommendations in a public report. During Phase 2, it will provide ongoing support and expert guidance to Ambulance Victoria as it implements the Phase 1 recommendations. And during Phase 3 , the Commission will audit the extent to which Ambulance Victoria has implemented those recommendations, again detailing its findings and any further recommendations in a public report.

Beyond permitting the Commission to enter into an agreement with the duty holder to conduct a review and to recover the reasonable costs of conducting that review, ${ }^{26}$ the Equal Opportunity Act does not prescribe how the Commission is to conduct a review. Rather, the
Commission is free to determine how best to conduct each review, having regard to Terms of Reference and agreed objectives.

Common to all large-scale reviews, however, is the collection and analysis of extensive data and documentation and broad-ranging stakeholder engagement. In the case of the final phase of the Victoria Police review, the Commission surveyed the entire police force, ${ }^{27}$ conducted 100 confidential interviews, facilitated 20 focus groups, received five written submissions, conducted five literature reviews and reviewed the organisation's workforce and complaints data, as well as thousands of pages of policies, procedures and other organisational material (Victorian Equal Opportunity and Human Rights Commission 2019). It is also common practice for the Commission to develop and apply its own research and coding frameworks tailored to the particular review, to support the collection and analysis of this information.

Other features of reviews typically adopted by the Commission include seeking ethics approval of its research methodology, when the review would pose more than a risk of discomfort to the review participants or it is otherwise required, and adherence to an internal review practice guideline, which comprehensively details the practices and procedures that Commission staff are expected to follow in conducting a particular review.

\subsubsection{REVIEW OUTCOMES: A CASE STUDY}

At the conclusion of a large-scale review, the Commission routinely publishes a report detailing the findings and recommendations arising from that review. ${ }^{28}$ Such reports are made publicly available on the Commission's website, in addition to being shared directly with the relevant duty holder and any individuals who participated in the review. Where provision is made for an audit, the Commission will subsequently publish a further report, detailing its findings and recommendations

\footnotetext{
${ }^{25}$ Equal Opportunity Act 2010 (Vic) s 151.

${ }^{26}$ Equal Opportunity Act 2010 (Vic) s 151(1A).

27 The Commission received 6026 completed survey responses.

28 The Commission does not usually publish a final report following smaller-scale uses of the review function, although such reviews often still result in a report provided to the requesting duty holder.
} 
in relation to the duty holder's progress in implementing the Commission's recommendations.

Beyond the final report itself, reviews have the potential to be a catalyst for significant structural and culture change. The Victoria Police review is illustrative of the potential outcomes when exercising the review function in section 151 and its facilitative approach to compliance with the Equal Opportunity Act. This particular review came about in response to compelling evidence that many Victoria Police female employees were experiencing sex discrimination and sexual harassment at work. Victoria Police acknowledged the need to address its internal culture and structures in order to improve both the lived experiences of its female employees and its capability to serve the community effectively, including when responding to gender-based violence against women.

The review proceeded in three phases.

Phase 1, delivered in 2015, examined the nature, extent, drivers and impacts of sex discrimination and sexual harassment, including predatory behaviour, in Victoria Police (Victorian Equal Opportunity and Human Rights Commission 2015). It found that this conduct was widespread and normalised in the organisation, profoundly harming the organisation's female employees, and that many perpetrators had not been held accountable for their actions or abuses of power. The Commission's research revealed structural and cultural barriers to gender equality, including a rigid, hypermasculine policing identity that normalised everyday sexism and embedded gender inequality and systemic discrimination.

Phase 2, delivered in 2017, audited the extent to which the 20 recommendations made by the Commission in its Phase 1 report had been implemented (Victorian Equal Opportunity and Human Rights Commission 2017). An interim audit, the Commission found that Vic- toria Police and the Victorian Government had begun implementing a broad package of reforms, but the extent of the remaining effort needed to implement the significant body of intersecting reforms in a large and complex organisation, was considerable.

Phase 3, delivered in 2019, again audited progress against the Commission's Phase 1 recommendations and also assessed the state of gender equality in Victoria Police (Victorian Equal Opportunity and Human Rights Commission 2019). The Commission's final report on the review revealed an organisation that had changed in some very fundamental ways, not only in its policies and processes, but also in its policing identity and culture, reflecting the substantial resources, leadership and strategic consideration that Victoria Police had dedicated to achieving gender equality. The Commission found that women were being paid more fairly, with an almost 2 per cent reduction in the organisation's gender pay gap. The proportion of employees making use of flexible work arrangements had risen, up almost 11 per cent for women and almost 9 per cent for men. Women's representation at various ranks and roles had increased, including, for instance, at the Command level, where women comprised 40 per cent of appointments between 2015 and 2018. A parental leave backfill scheme had been established, ensuring better support for female employees during pregnancy and return-towork and reduced stigma around pregnancy and care. Employees were better educated about sex discrimination and sexual harassment, with close to 92 per of the organisation participating in workplace harm training. Work was underway to improve how Victoria Police responds to workplace harm when it does occur and, at the time the Commission published its final report, the Victorian Government had announced the establishment of a Redress and Restorative Engagement Scheme for police employees who have experienced sex discrimination and sexual harassment, including predatory behaviour (Victorian Government 2019). ${ }^{29}$

\footnotetext{
29 The scheme started receiving applications from 12 December 2019. As at 30 June 2020, it was supporting 181 participants, 141 of whom had submitted a complete application. See Department of Justice and Community Safety, Annual Report 2019-20 (State of Victoria, 2020) 16.
} 
Notwithstanding these and other significant accomplishments, the Commission found that Victoria Police still had work to do to embed gender equality across its organisation - discrimination persisted in the organisation and the threat of sexual harassment remained real. The Commission reached these findings while acknowledging that the type of transformative change that Victoria Police is striving for will take ongoing work and sustained commitment to embed gender equality in every part of the organisation.

While acknowledging the work remaining, the review demonstrated what is possible when a duty holder, like Victoria Police, treats the positive duty to eliminate sex discrimination, sexual harassment and victimisation seriously and takes advantage of the review function as means of strengthening its capability to comply with the Equal Opportunity Act and achieve workplace equality. It is therefore a welcome development to see that Victoria Police - with its strengthened capability - has continued to progress its reform agenda following the end of the Commission's review. Mostly notably, this ongoing commitment has seen Victoria Police establish the Gender Equality and Inclusion Command and publish Equal, Safe \& Strong: Victoria Police Gender Equality Strategy 2020 - 2030 (Victoria Police 2020).

\subsection{A REGULATORY TOOL TO PROMOTE TRANSPAR- ENCY AND EQUALITY}

The ability to achieve transparency and, through it, equality, from any particular review begins from the moment that the Commission starts discussing a potential review with a duty holder (What is the review going to examine? How will the review be conducted and what, if any limits might be agreed?). It is cemented when the Terms of Reference are agreed upon and it is given life as the research, analysis, policy development and reporting unfold. Without doubt, reviews provide an unparalleled opportunity to engage extensively with a duty holder's workforce, to examine their policies and procedures, their workforce and complaints data much of which is not usually publicly available, particularly in closed institutions - and to speak to its leaders and others about its compliance with the Equal Opportunity Act.

The publication by the Commission of its final report arising from a review enables transparency around its findings and recommendations. More broadly, it provides the community with a rare and detailed insight into the state of equality in the duty holder's organisation. Take Victoria Police, for example, an organisation whose day-to-day work is carried out in the public eye, but which, in many ways, is a closed organisation. The three comprehensive reports published by the Commission provided those outside Victoria Police with one of the most detailed insights ever seen into the state of equality in the organisation. In 2019, at the launch of the final report of the Victoria Police review, (then) Commissioner Kristen Hilton (2019) credited Victoria Police's commitment to transparency as critical to its success in achieving demonstrable change towards workplace equality. She reflected that "a key part of the progress [that] the organisation has made towards gender equality has been because this work has been done in the open".

The openness and transparency that comes from a public report also helps to ensure the accountability of the duty holder for implementing the Commission's recommendations - irrespective of whether the Terms of Reference make provision for a subsequent audit - and enables the sharing of learnings that may support other duty holders to strengthen their compliance with the Equal Opportunity Act. Indeed, throughout the Victoria Police review, both the Commission and Victoria Police were acutely aware that many other organisations, even policing organisations overseas, were watching what the review might yield. It is also conceivable that any learnings arising from a review under the Equal Opportunity Act might also support compliance with other legislation, including, for instance, the Gender Equality Act 2020 (Vic), where it is related to workplace gender equality.

The voluntary nature of reviews, whereby the exercise of the function is contingent on a duty holder first 
inviting the Commission to conduct a review, suggests that most duty holders who request such a review will be predisposed to implementing transformative change and being open and accountable in the process. However, the reality is far more complex. A duty holder seemingly committed to change at the beginning of a review may be confronted by the seriousness and scale of unlawful conduct revealed during a review, at a minimum prompting nervousness about the release of that information publicly, fearing the reputational, legal and other risks that may emerge from opening up their organisation in the manner originally intended.

Herein lies the challenge for the Commission in using the review function to promote transparency and equality. Duty holders have to be willing to come forward to request its help and they have to remain committed to the process throughout. That is why the Commission's independence and the integrity of its research and prior reviews are so important for promoting transparency through the exercise of section 151 of the Act. And, yet, the Commission knows first-hand that the leadership and courage required to take this step, can be transformative for a duty holder and, as in the case of Victoria Police, result in significant, demonstrable change. For those not even willing to come forward in the first place, despite significant non-compliance with the Act, greater enforcement and compulsion powers for the Commission are essential. At the very least, it may be necessary for the Commission to exercise its investigation function, provided the relevant threshold requirements can be satisfied.

Somewhat paradoxically, in order to achieve the eventual promise of transparency that section 151 offers, the Commission must simultaneously prioritise and practice confidentiality. Simply put, the effectiveness of a review in promoting compliance with the Equal Opportunity Act is dependent on a deep level of trust and confidence that the Commission will conduct its reviews professionally and sensitively and maintain appropriate safeguards for the collection, analysis and recording of confidential and sensitive information. In order to build the trust required for the Commission to receive information of this kind, it must operate with the promise and expectation of confidentiality of communications. The Commission routinely takes a number of precautions to ensure appropriate information is kept confidential and trust is maintained, including deidentifying participant information when publishing quotes and narratives in its final reports and even then, only doing so with the express consent of the participant.

In discussions with organisations who are considering a review, confidentiality is always front of mind. Reviews require that organisations share sensitive information and data and open themselves up to an assessment of their performance on issues that are by their nature often sensitive and controversial. While organisations engage the Commission to learn and improve their programs and practices, they regularly seek a level of assurance and agreement regarding how any information will be shared publicly. The Commission is able to reassure organisations that it can maintain confidentiality, pointing to work that it has done in the past for other organisations and to the secrecy provision in section 176(3) of the Equal Opportunity Act. ${ }^{30}$ In the Commission's experience, this provides a level of comfort that allows organisations to have confidence that it is a trustworthy recipient of their information.

\subsection{EARLY LESSONS FROM COMPLETED REVIEWS}

While the Commission has conducted numerous smaller-scale reviews using section 151 of the Equal Opportunity Act, its use of the function for larger-scale reviews is comparatively young. Even so, a number of lessons have begun to emerge from completed reviews, that provide insight into how section 151 can be best leveraged to promote transparency and achieve equality.

First, to be effective, reviews require a deep and continued commitment from the duty holders' senior

\footnotetext{
${ }^{30}$ The secrecy obligation in section 176(3) prohibits the disclosure of information unless it is necessary for the purposes of, or in connection with, the performance of a function under the Equal Opportunity Act. Section 176A provides an exception in cases where consent is provided.
} 
leaders, specifically those leaders who are capable of influencing organisational culture and organisational change. Reviews involve the Commission working closely with those leaders, educating them about the organisational changes needed and helping them to understand the importance of their sustained leadership commitment in achieving change.

Second, effective reviews depend on organisational buy-in. When conducting reviews, the Commission seeks to enable reform by ensuring that recommended changes are supported by the whole organisation; they cannot be conceived of solely as a 'HR issue'. The Commission also seeks to align any recommended changes with the corporate and strategic needs of the organisation, when appropriate, thereby encouraging organisational commitment.

Third, the success of a review depends on there being a relationship of deep trust and collaboration with the duty holder, carefully balanced so as to enable the Commission to remain independent and be critical when needed. While a seemingly difficult balance to achieve from the outside, in the Commission's experience, it is this balance that sets the duty holder up for the greatest chance of success in achieving transformative change. It is this balance that is the very essence of the facilitative approach to compliance with the Act.

Fourth, reviews best support the goals of transparency and equality when the Commission engages widely, collects extensive data and adopts leading practice approaches to its research. It is the richness of the information gained through the exercise of the review function, the detailed insight it affords into the organisation and the issues it is facing and the opportunities to identify practical and tailored solutions, that enable reviews to create meaningful change - change that ultimately supports compliance.

Finally, to be effective, reviews must be well resourced and funded accordingly, both within the Commission and the duty holder's organisation. In the case of the Victoria Police review, the Commission worked closely with the organisation to ensure it clearly understood the scale of the organisational effort needed to change and resourced the work accordingly.

\section{CONCLUSION}

The Commission was first vested with the independent review in section 151 in 2010. Now just over 10 years young, the exercise of this function to enable large-scale reviews of the kind seen in Victoria Police and presently in Ambulance Victoria remains comparatively new, especially when contrasted to its use in smaller-scale reviews or even other regulatory functions. And, yet, there is an emerging and highly compelling body of evidence demonstrating that large-scale reviews conducted under section 151 are a powerful tool for promoting transparency and, through it, equality - especially when accompanied by a public report detailing the Commission's findings and recommendations. The Commission's current review into Ambulance Victoria, the endeavour to shine a light on and ensure accountability for the human rights issues within the organisation, provides an opportunity to further explore the linkages between section 151 and the goals of transparency and equality. It will see the Commission examine the culture, attitudes, structures and identity of the organisation, in effect the organisation's very essence or fabric, and share its findings and recommendations publicly.

Still, there is more to learn about these connections and, specifically, how the review function in section 151 can facilitate transparency, while also respecting the need for the Commission to prioritise and practice confidentiality. What, for example, can we learn from the way that Royal Commissions and other bodies of inquiry balance the sometimes competing interests of transparency and confidentiality? Should the Commission only agree to conduct a large-scale review if the duty holder agrees that the Commission can publish its findings and recommendations in a public report? What considerations might justify an agreement between the Commission and the duty holder not to openly share the findings and recommendations arising from a section 151 review? These are just some of the questions that the 
Commission must now grapple with as the review function continues to mature into its second decade in operation.

\section{REFERENCES}

1. Ashton, G. 2019. "Independent review into Victoria Police - Phase 3, YouTube, 26 August 2019, https://www.youtube.com/watch?v=GYnbXqaLOLI.

2. English, C. 2020. Finding into death with inquest (Tanya Louise Day), COR 2017 6424, Coroners Courts of Victoria, 9 April 2020, 108.

3. Gardner, G. 2008. An equality act for a fairer Victoria: Equal opportunity review final report. State of Victoria.

4. Department of Justice and Community Safety (2020). Annual Report 2019-20 (State of Victoria, 2020).

5. Hilton, K. 2019. Launch of Independent review into sex discrimination and sexual harassment, including predatory behaviour, in Victoria Police: Phase 3 audit and review, Melbourne, 27 August 2019.

6. Lay, K. 2020. Letter to Victorian Equal Opportunity and Human Rights Commissioner, re Independent review into workplace equality in Ambulance Victoria, 2 December 2020.

7. McGregor, S. 2019. Finding into death without inquest (John Edwin Wilks), COR 2017 4263, Coroners Courts of Victoria, 19 March 2019, 18.

8. Tuohy, W. 2020a. "Sex discrimination and harassment widespread in Ambulance Victoria, say paramedics", The Age, 26 October 2020, https://www.theage.com.au/national/victoria/sex-discrimination-and-harassment-widespread-in-ambulance-victoria-say-paramedics20201025-p568h5.html

9. Tuohy, W. 2020b. "They wrote her number on public toilet walls all up and down the Calder Highway'”, The Age, 27 October 2020, https://www.theage.com.au/national/victoria/they-wrote-her-number-on-public-toiletwalls-all-up-and-down-the-calder-highway20201027-p5693f.html
10. Tuohy, W. 2020c. "Human Rights Commission to probe reports of sex discrimination, harassment at Ambulance Victoria", The Age, 27 October 2020,

https://www.theage.com.au/national/victoria/human-rights-commission-to-probe-reports-of-sex-discrimination-harassment-at-ambulance-victoria-20201027-p568zs.html

11. Victorian Equal Opportunity and Human Rights Commission. 2021. Terms of Reference of the Independent review into workplace equality in Ambulance Victoria, endorsed by Ambulance Victoria Board on 30 November 2020, available at https://www.humanrights.vic.gov.au/stati c/1a5bbe1046a5ebd49326e657f8f80e49/ Terms-of-Reference-Endorsed-by-AVBoard-30-November-2020-002.pdf

12. Victorian Equal Opportunity and Human Rights Commission. 2020. Guideline: Preventing and responding to workplace sexual harassment; Complying with the Equal Opportunity Act 2010. State of Victoria.

13. Victorian Equal Opportunity and Human Rights Commission. 2019. Independent review into sex discrimination and sexual harassment, including predatory behaviour, in Victoria Police: Phase 3 audit and review. State of Victoria.

14. Victorian Equal Opportunity and Human Rights Commission. 2017. Independent review into sex discrimination and sexual harassment, including predatory behaviour, in Victoria Police: Phase 2 audit. State of Victoria.

15. Victorian Equal Opportunity and Human Rights Commission. 2015. Independent review into sex discrimination and sexual harassment, including predatory behaviour, in Victoria Police: Phase one report. State of Victoria.

16. Victorian Government. 2019. "Restorative Engagement and Redress Scheme",

https://www.vic.gov.au/redress-police-employees.

17. Victorian Ombudsman. 2018. Investigation into the imprisonment of a woman found unfit to stand trial (State of Victoria, 2018) 
18. Victorian Ombudsman, 2017. Implementing OPCAT in Victoria: Report and inspection of the Dame Phyllis Frost Centre (State of Victoria, 2017).

19. Victoria Police. 2020. Equal, Safe \& Strong: Victoria Police Gender Equality Strategy 2020- 2030 (State of Victoria, 2020).

\section{Legislation}

Change or Suppression (Conversation) Practices Prohibition Act 2021 (Vic)
Charter of Human Rights and Responsibilities Act 2006 (Vic)

Equal Opportunity Act 2010 (Vic)

Gender Equality Act 2020 (Vic)

Inquiries Act 2014 (Vic)

\section{Case law}

United Firefighters Union of Australia v Victorian Equal Opportunity and Human Rights Commission [2018] VSCA 252 